\title{
Innovation of the Polish Economy in comparison to European Union countries
}

\author{
Dorota Miłek $^{1, *}$, and Marta Mistachowicz ${ }^{2}$ \\ ${ }^{1}$ Kielce University of Technology, Faculty of Management and Computer Modelling, al. Tysiąclecia Państwa Polskiego 7, 25-314 \\ Kielce, Poland \\ ${ }^{2}$ Kielce University of Technology, Faculty of Management and Computer Modelling - graduate, al. Tysiąclecia Państwa Polskiego 7 , \\ 25-314 Kielce, Poland
}

\begin{abstract}
Knowledge and innovation are fundamental drivers of development processes. This is affirmed by a reorientation of the European Union policies for 2014-2020, which consider a more dynamic construction of economy based on knowledge and innovation, a more effective use of pro-innovative resources, and the strengthening of innovation systems are as basic dimensions of economic activity. The purpose of this paper is to analyse and assess the level of Poland's innovation as compared to the European Union countries in 2011 and 2015. To assess innovation, expenditure on research and development (R\&D) activity was employed, along with the employment levels in R\&D and indices referring to the effects of innovation activities in the form of protection of intellectual and industrial property. As a result of the study, clusters of countries with the highest and lowest innovation level were identified. The study is supplemented by Ward's clustering method, which forms the basis for separation of similar countries with respect to an analysed phenomenon. The calculations were carried out with the use of Statistica 13 programme.
\end{abstract}

\section{Introduction}

In the modern economy, innovations play a crucial role. In a long-term perspective, both the development and the competitiveness of individual member states of the European Union are, to a significant degree, related to the growth in their innovation level. Regional development in the modern economy is driven by three inter-related categories: innovation, entrepreneurship and competitiveness, with knowledge being the factor that unites them $[1,2,3,4]$. Changes in the level of innovation enable assessing the efficiency of the pursued innovation policy and identifying the areas that require necessary measures. This found its expression in the EU cohesion policy where importance in innovation creation is currently attributed to endogenous factors that should contribute to the development of innovation. The development of innovation relies on the concept of smart specialisation $[5,6]$. "It is the specific resources of the region, incorporated in the global processes, that currently become the key success factor [7]."

The purpose of the paper is to analyse and assess the level of Poland's innovation as compared to the European Union countries in 2011 and 2015. The multitude and the variety of factors that influence innovation results in the fact that its assessment calls for the use of a set of indices reflecting various aspects of innovation activities of the economy [3, 8, 9]. Therefore, to assess innovation, expenditure on research and development (R\&D) activities were used, along with the employment levels in $R \& D$ and indices referring to the effects of innovation activity. The study is supplemented by Ward's clustering method, which provides the base for separation of similar countries with respect to the analysed phenomenon.

\section{Methodology}

The innovation of the European Union member states was assessed on the basis of analysis of differences in the level of selected available indices and the use of Ward's method [10], which was utilised to determine the similarities of regions of the European Union with respect to their innovation potential. The analysis refers to 2015 full and current access to statistical data and 2010, which provide a point of reference for showing changes in the level of innovation of the European Union regions. As a supplement, Ward's agglomerative clustering method was used, which enables separating similar regions with respect to an analysed phenomenon. Among other agglomerative methods, the one in question is distinguished by the use of variance analysis to quantify the distance between clusters. It is considered a reliable, efficient and broadly-applied method in analyses pertaining to the development of regions $[11,12,13]$. As a result of the analysis, a tree diagram is received, which is a graphic interpretation of the received results.

\section{Comparison of innovativeness of the Polish economy with the European Union countries}

Innovation on the level of countries and regions is characterised, to a significant degree, by expenditure on

\footnotetext{
* Corresponding author: dorothy@tu.kielce.pl
} 
research and development (R\&D) activities, along with employment in R\&D. Indices referring to the effects of innovation activities in the form of protection of intellectual and industrial property are also significant.

\subsection{Expenditure on Research and Development Activities}

Research and development activity is the main link of knowledge and a factor responsible for socio-economic development. A significant element of innovative activity is expenditure on research and development. The value of domestic expenditure on $R \& D$ is the basic measure that allows making assessments and comparisons of sizes of research and development activity. The value of domestic expenditure on R\&D per resident in the European Union countries in 2011 and 2015 is presented in Fig. 1. Poland, as compared to other EU countries, had a relatively low domestic expenditure on R\&D [14]. In 2011, it was only on the level of $14.4 \%$ and in 2015 on the level of $19.1 \%$ of the average EU expenditure. A similar level of expenditure on R\&D was recorded in such countries as Cyprus, Lithuania and Croatia. On the other hand, in 2015, the highest value of expenditure in this respect was recorded in Sweden, namely EUR 1,504.30 per resident, which exceeded the Polish expenditure 13 times. In 2015, Poland recorded an increase in expenditure on R\&D from the level of EUR 74.5 to EUR 113.6 per resident, i.e. in comparison to 2011 , by $52.5 \%$. Nevertheless, such growth did not result in a change in Poland's position in the ranking with respect to the expenditure on $R \& D$ as compared to GDP (in both analysed years in this aspect Poland occupied the $21^{\text {st }}$ position).

The index of intensity of R\&D work amounting to $1 \%$ in 2015 constituted only $49 \%$ of the average EU value (Fig. 2) [14]. Only two countries, Sweden and Austria, fulfilled the guidelines of "Europe 2020 Strategy" in 2015 , which assumes the share of expenditure on R\&D in relation to the GDP on the level of $3 \%$ (Poland's domestic target was on the level of $1.7 \%$ ). In order to accomplish the intended target share of R\&D expenditure in relation to the GDP in Poland, it should grow by $0.7 \%$ over the course of five years. Disproportions in the size of expenditure on $R \& D$ result primarily from the affluence of individual countries (GDP per capita).

Countries considered the most innovative are characterised by a significant share of expenditure on R\&D incurred by the sector of business enterprises. In 2015, it oscillated around 20\% - 69\% (Fig. 3). At that time, Poland occupied the $20^{\text {th }}$ position with the value of $39.0 \%$ and it was lower by $16.3 \%$ in comparison to the EU average (55.3\%) [14]. Leading positions were taken by Slovenia $(69.2 \%)$ and Germany $(65.6 \%)$.

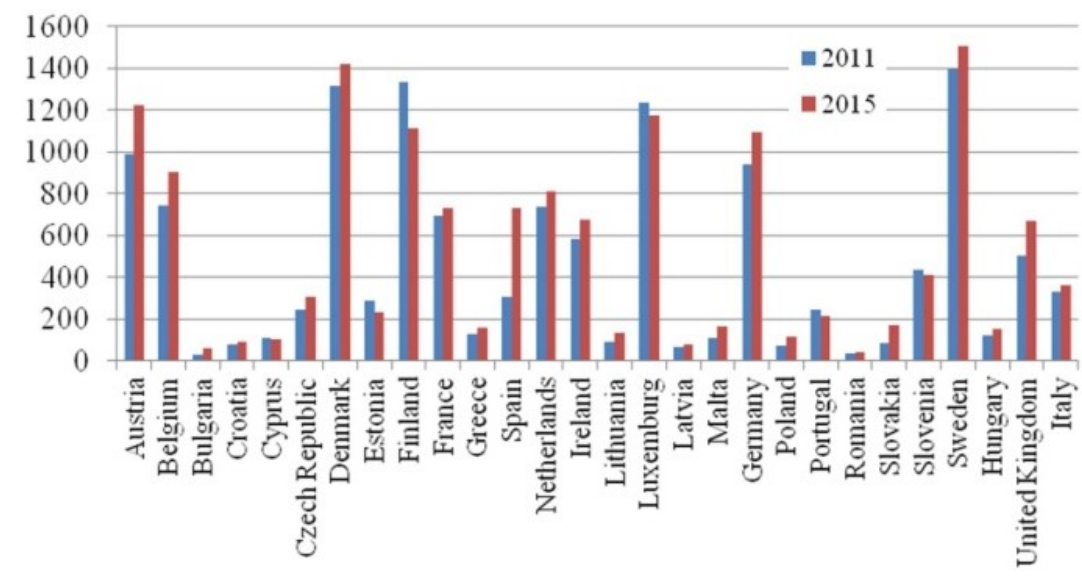

Fig. 1. GERD: gross domestic expenditure on R\&D per resident (in the EU) in 2011 and 2015.

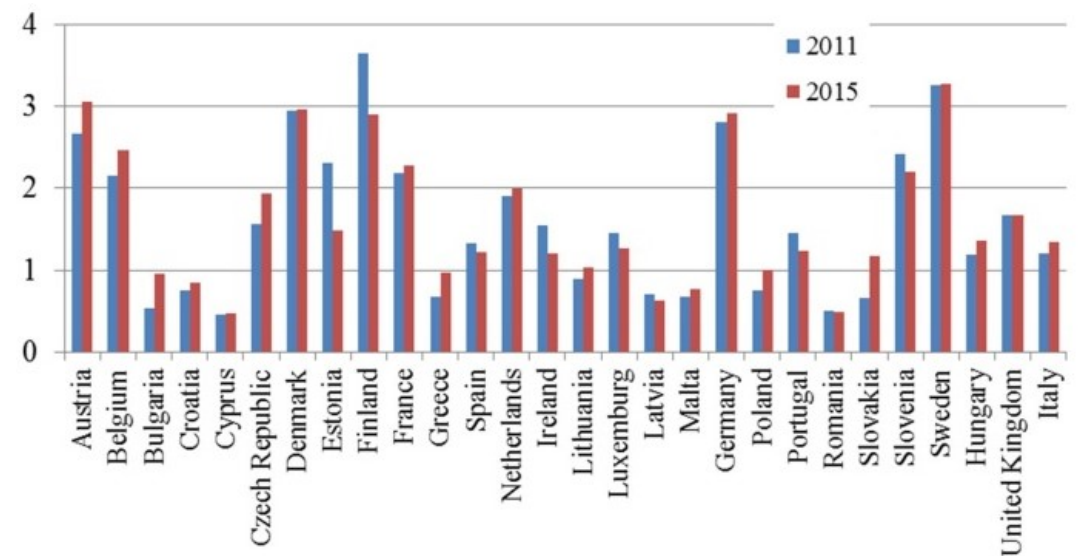

Fig. 2. Gross domestic expenditure on R\&D (GERD) in relation to GDP (in \%). 


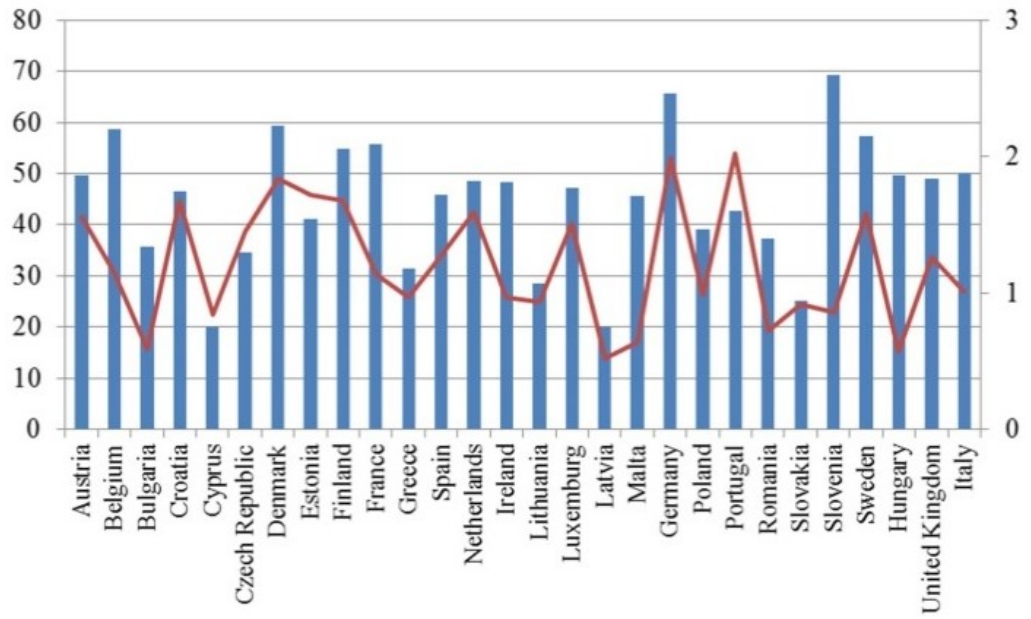

Share of expenditure on R\&D financed by the business enterprise
sector in total expenditure on R\&D (\%)
GBAORD as \% of total government expenditure

Fig. 3. Share of R\&D expenditure financed by the sector of business enterprises in total expenditure on R\&D (\%) and government budget appropriations or outlays for R\&D as \% of total government expenditure in 2015 .

The highest value of the index of share of government budget appropriations or outlays for R\&D in total government expenditure was recorded for Portugal on the level of $2.02 \%$; Portugal, similarly to Poland, was included in the cluster of countries with a low level of innovation, and for Germany (1.99\%) - Fig. 3. Expenditure on R\&D incurred by the Polish government in 2015 amounted to $0.98 \%$ of the total government expenditure, i.e. $0.4 \%$ - less in comparison to the EU average $(1.38 \%)$. The lowest value of this index was recorded in Latvia $(0.5 \%)$.

In relation to the relatively low innovation of Polish regions, and thus of the entire economy, manifested in small, yet continuously growing expenditure on $\mathrm{R} \& \mathrm{D}$, there is an urgent need for activities aimed at its intense improvement.

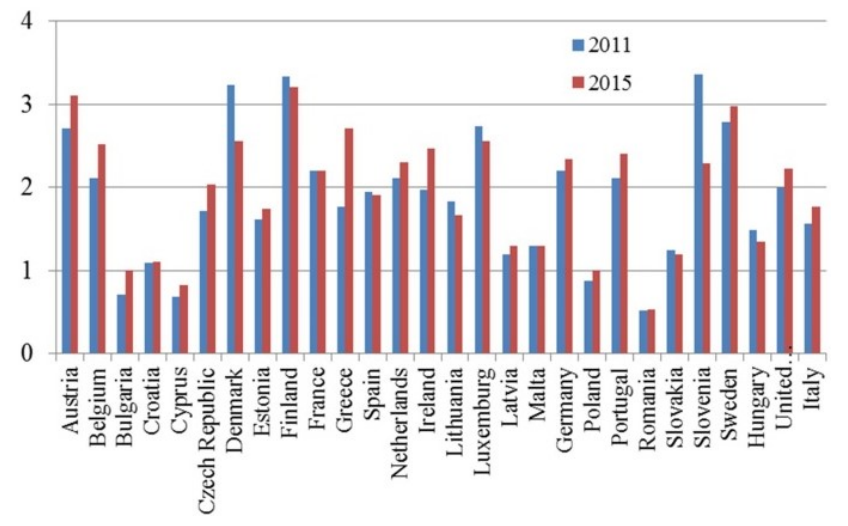

Fig. 4. Share of R\&D employment in total employment (in $\%)$ in 2011 and 2015.

\subsection{Employment in R\&D sector}

Apart from expenditure, employment in R\&D is another significant measure of the level of innovation (Fig. 4). Countries with the highest percentage of R\&D employment as compared to total employment included Finland, Austria, Sweden, Greece and Luxembourg [14]. The level of employment in such countries ranged from $2.5 \%$ to $3 \%$ in 2015 . For Poland, this value was one of the lowest in the study. In 2015, together with Bulgaria, Poland took the third position from the bottom: the share of R\&D employment in total employment reached the level of only $1 \%$, i.e. lower by over a half from the average EU value. R\&D employment in Poland as compared to the majority of EU countries is thus on a definitely low level.

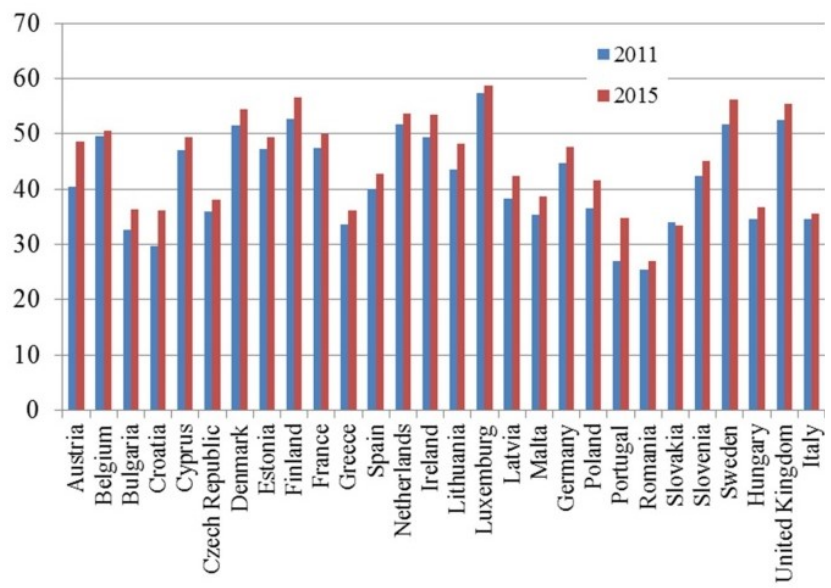

Fig. 5. HRST: human resources in science and technology as \% of active population in 2011 and 2015. 
Human resources in science and technology, which are fundamental to the knowledge-based economy, constitute an important innovation index. In this study, the index is used for the 25 - 64 age group, taking into account this part of the population which completed tertiary level education or is employed in science and technology and is expressed as the percentage of the active population aged $25-64$. The measure determined in this manner has an increasing tendency in the EU. In the Polish economy, the index grew from the level of $36.6 \%$ in 2011 to $41.6 \%$ in 2015 (Fig. 5). The dominant country with respect to the percentage of human resources in active population was Luxembourg, which in 2015 accomplished the level of $58.8 \%$, being ahead of the EU average by 13.65 [14]. Nevertheless, it should be stressed that in both examined years, $50 \%$ of member states failed to accomplish the EU average. A relatively high level of qualified personnel in Poland as compared to certain EU countries shows a significant potential of the R\&D sector.

\subsection{Effects of innovation activities in the form of protection of intellectual and industrial property}

The innovative potential of the economy is also related to the protection of intellectual property, which has a fundamental significance in the area of competition of foreign business enterprises. It is expressed by indices of intellectual property protection, including the number of patent applications to the EPO or the applications for the European Union trademarks (EUTM). In both analysed years, Poland took the $20^{\text {th }}$ position with respect to the number of patent applications to the EPO per million residents. The number of patent applications in 2014 in comparison to 2011 grew by $58 \%$ (from the level of 10.11 to 16.02 per million residents) [14].

In the case of the EU average, a 2\% drop was recorded with respect to the number of patent applications (from 113.87 to 111.97 ) [14]. It should, however, be emphasised that in spite of the growth in the number of patent applications of Polish entities, this number still significantly differs from the EU average. Sweden, Finland and Germany are the definite leaders, where patent applications reached the level of 250 - 350 per million residents. A majority of Polish entities applying for protection of inventions did not use the European Patent Office, but the Patent Office of the Republic of Poland.

For comparison, the number of applications to the EPO in 2014 amounted to 16.02 per million residents and the number of applications to the Patent Office of the Republic of Poland reached the level of 102.4 per million residents. It is worrying to note that business enterprises in Poland are characterised by low patent activity, in contrast to developed, innovative economies, where this sector is responsible for the creation, as well as commercialisation of inventions. In Poland, the patent activity characterises primarily research and academic centres. A small number of patent applications translates to a relatively weak position of the Polish economy with respect to the protection of innovations.

It is, therefore, necessary to make the entrepreneurs aware of the benefits that are brought by the protection of industrial property, which may form a premise for increasing their competitiveness.

Poland's situation in the context of applications for the European Union trademarks is analogous. The number of applications submitted by Polish entities in 2015 amounted to 96.38 per million residents, which constituted $54.8 \%$ of the EU average [14]. The dominant country with respect to the number of registered trademarks is Luxembourg, with a result of over 2000 applications per million residents, which is over 22-times higher in comparison to Poland. Thus, Luxembourg's position in the context of the innovation level is determined by a high level of industrial property. A small number of trademarks registered in Poland results primarily from low awareness of entrepreneurs. They often lack knowledge about how to protect their brands, and, on account of this, are exposed to unfair competition.

\section{Comparative analysis of innovation of European Union countries with the use of Ward's method}

In order to identify similar EU regions with respect to the level of innovation, they were clustered with the use of Ward's method on the basis of 10 variables. Selection of specific measures of the level of innovation in regions results from the objective of the study and analysis methods. It depends both on the availability of data and arbitrary decisions of the researcher. The basic source of information was the Eurostat database [14]. Moreover, materials available in the database of the Research and Innovation Observatory of the European Commission [15] and the World Bank [16] were used. To examine the level of innovation, the following indices were selected, nine of which are presented in relative values:

$X_{1}-G E R D$ per resident (in EUR); $X_{2}-G E R D$ in relation to GDP (in \%); $X_{3}$ - share of expenditure on $R \& D$ financed by the business enterprise sector in total expenditure on R\&D (in \%); $X_{4}-G B A O R D$ as \% of total government expenditure; $X_{5}$ - employment in $R \& D$ in FTE; $X_{6}$ - share of employment in $R \& D$ in total employment; $X_{7}-H R S T$ as \% of active population; $X_{8}-$ patent applications to the European Patent Office (EPO) per million residents; $X_{9}$-applications for the European Union trademarks (EUTM) per million residents; $X_{10}-$ share of high technology product export in total export.

Based on the characteristics adopted in 2011, five clusters of relatively homogeneous spatial units were created - linkage distance on level 5 (Fig. 6).

The first cluster is made up of five EU regions: Austria, Germany, Denmark, Finland and Sweden, which clearly stand out among other countries with respect to higher values of indices in the area of innovation. These features include: GERD per resident (in EUR), GBAORD as $\%$ of total government expenditure and patent applications to the European Patent Office (EPO) per million residents. On the other hand, the next cluster features only Luxembourg (cluster 2), which is characterised by the highest value of GERD per resident (in EUR) 1,233.60 and the highest number of applications for the European Union trademarks (EUTM) per million residents $(2,119.80)$. 


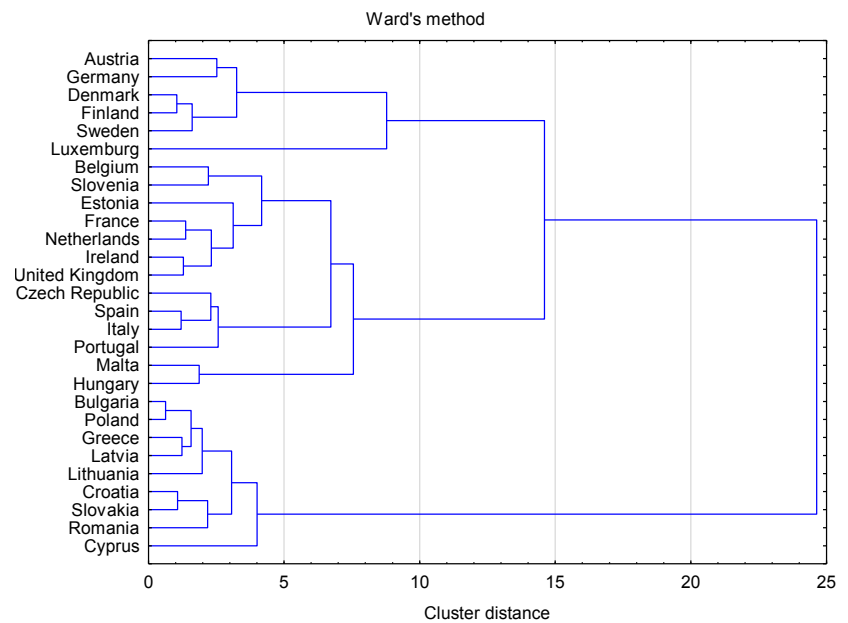

Fig. 6. Similarity of EU countries with respect to innovation in 2011 based on Ward's method.

Cluster 3 includes seven countries: Belgium, Slovenia, Estonia, France, the Netherlands, Ireland and United Kingdom. The next cluster, which contains the Czech Republic, Spain Italy and Portugal makes up cluster 4. Malta and Hungary form a two-element cluster and show similarities in the level of innovation for the following features: $X_{1}, X_{3}, X_{4}, X_{6}$ and $X_{7}$ (cluster 5). The last cluster (6), which also includes Poland, encompasses such countries as: Bulgaria, Greece, Latvia, Lithuania, Croatia, Slovakia, Romania and Cyprus (the group constitutes over $32.0 \%$ of the examined countries). However, it should be emphasised that every EU country that was included in this cluster is characterised by certain specific features and may be examined separately. Clustering of countries may offer a basis for further in-depth studies.

The result of clustering of EU countries with similar levels of innovation in 2015 is a tree diagram presented in Fig. 7. Six clusters of relatively uniform spatial units were distinguished (linkage distance on the level of 6.5). The first cluster includes, similarly to 2011, Austria, Denmark, Sweden, Finland and Germany. This cluster was created on the basis of similar values of the following features: $X_{1}$, $X_{2}$ and $X_{7}$. The second cluster includes the following countries: Belgium, Slovenia, France, United Kingdom, the Netherlands and Ireland. Luxembourg, analogously to 2011, belongs to a single-element cluster. The features that distinguish this country include the highest value of GERD per resident (in EUR) 1,176.50 and the highest number of applications for the European Union trademarks (EUTM) per million residents $(2,190.22)$. Another cluster which includes Bulgaria, Poland, Slovakia, Romania, Hungary, Greece, Lithuania and Latvia is the fourth cluster (the cluster constitutes only $30.0 \%$ of the examined countries). Cyprus and Malta make up the fifth cluster with two elements, which clearly differs with respect to the level of innovation in relation to other countries on account of low values of features $\left(X_{2}\right.$, $X_{3}, X_{4}$, and $X_{5}$ ). Croatia, Portugal, Spain, Italy, Czech Republic and Estonia are included in cluster 6 . The results of clustering may trigger further thorough studies aimed at determining which variables exerted a decisive impact on the classification of regions to individual clusters.
The received results of clustering of the EU countries with the use of Ward's method partially overlap with the positions of certain countries based on the Summary Innovation Index (SII) $[17,18]$. The leaders of innovation among the EU countries on the basis of SII are such countries as: Sweden, Denmark, Germany and Finland. In 2015, also the Netherlands joined this cluster. Based on the clustering analysis, Austria was included in the discussed group. The position of Cyprus and Estonia dropped. The SII in 2015 amounted to approx. $86 \%$ of the average value of the EU index in these countries, which allowed for including them in the group of moderate innovators. On the other hand, Lithuania and Latvia improved their results in 2015 as compared to 2011 and were promoted from the position of modest innovators to the level of moderate innovators. Countries that had the lowest results and, on account of this, were considered the least developed with respect to innovation are Bulgaria and Romania, which in 2015 only reached $46.4 \%$ and $34.5 \%$ of the average EU result, respectively.

In 2011 and in 2015, Poland was in the group of moderate innovators, occupying the $24^{\text {th }}$ and the $23^{\text {rd }}$ position, respectively. Bearing in mind a drop in the SII by 0.004 points, it might seem that the level of Poland's innovation deteriorated. However, it has to be analysed in reference to the average result of the EU. Relative efficiency of Poland's SII grew by $1.1 \%$ (from $54.9 \%$ in 2011 to $56 \%$ in 2015). Thus, Poland's position slightly improved, even though Poland had one of the lowest results among the EU member states. In 2015, apart from Lithuania and Latvia, i.e. countries right behind Poland in the ranking, the group of moderate innovators also included Croatia. Nevertheless, it should be remembered that the position of Poland as a moderate innovator is still very weak. This may be exemplified by the systematically dropping percentage share of the SII in the average value for the entire cluster. It may even be claimed that Poland is at the threshold of being moved to the least advanced cluster with respect to innovation advancement [19].

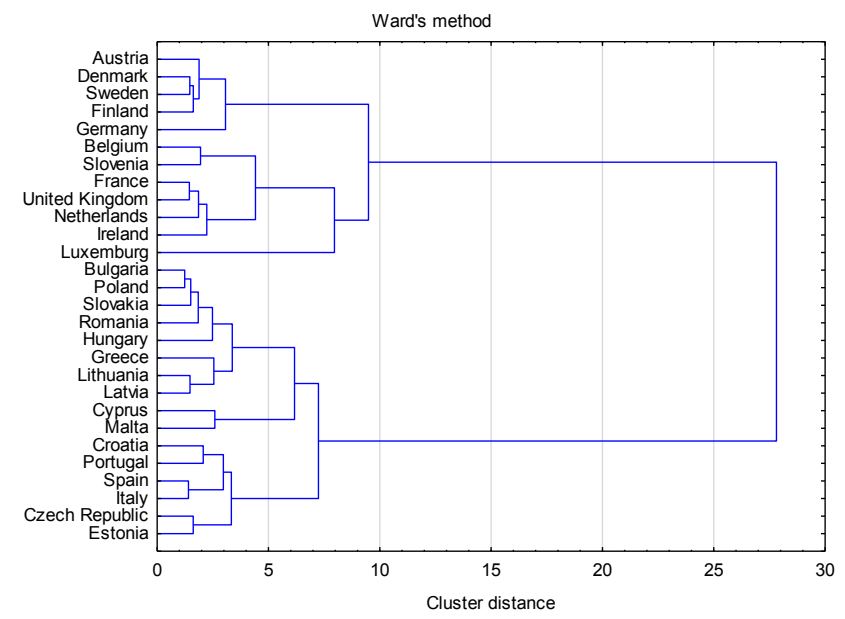

Fig. 7. Clusters of the European Union countries with similar level of innovation in 2015 . 


\section{Conclusions}

The comparative analysis and evaluation of the level of Poland's innovation with the European Union countries leads to the following conclusions:

1. Based on the expenditure on research and development activity, the highest positions in 2011 were taken up by Sweden, Finland, Denmark, Luxembourg and Austria, whereas the lowest by Bulgaria and Romania. In 2015, the following countries were the leaders: Sweden, Denmark, Austria, Luxembourg, Finland and Germany. Similarly to 2011, Bulgaria and Romania scored the lowest.

2. In 2011, the highest level of employment in R\&D as compared to total employment was recorded in Slovenia, Denmark, Finland and Luxembourg, whereas in 2015 in Finland, Austria and Sweden. The lowest values of the analysed index in both analysed years were recorded in Romania, Cyprus and Bulgaria.

3. In the light of innovation indices, Poland's position as compared to the European Union countries is not favourable. Poland's accomplishments in individual aspects of innovation are relatively meagre. The causes of Poland's low innovation level is to be primarily searched for in the inefficient system of financing, related to incurring relatively low expenditure on R\&D activities by private entities, coupled with low innovative activities of business enterprises. Furthermore, the studies showed the necessity of increasing the awareness of intellectual property protection.

In the European Innovation Scoreboard 2017 report, Poland ranked 25th (out of 28 EU countries) [20]. This is a decrease by two positions compared to the 2016 ranking. Croatia, Bulgaria and Romania came last in the classification. Despite the declining position, Poland still belongs to the group of moderate innovators. The opportunity to improve the innovativeness of the Polish economy is perceived in the so-called small act on innovativeness, which has been effective January 1st 2017. The distance between Poland and the most innovative countries, according to the provisions of the act, can be reduced, among other things, by introducing the system of rewarding instruments and encouraging to undertake innovative activities (in particular tax reliefs), stabilising the financing of commercialisation of research results or by procedural facilitation.

\section{References}

1. E. Łaźniewska, M. Gorynia (ed.), Konkurencyjność regionalna. Koncepcja-strategie-przyktady (PWN, Warsaw, 2012)

2. D. Grego-Planer, W. Glabiszewski, Manage. 20, 24 (2016)

3. I. Łącka, Procedia - Soc. and Behav. Sci. 213, 185 (2015)

4. S. Metcalfe, R. Ramlogan, Q. Rev. Econ. Financ. 48 433 (2008)

5. D. Milek, 25th Int. Conf. on Metallurgy And Materials, 1938 (2016)

6. T. Markowski, Studia KPZK PAN 155, 61-70 (2013)

7. M. Słodowa-Hełpa, Europa Regionum, XVII, 53-72 (2013)

8. W. Kasperkiewicz, Zeszyty Nauk. Pol. Tow. Ekonom. 9, 79-90 (2011)

9. W. Nasierowski, F.J. Arcelus, Procedia - Soc. and Behav. Sci. 58, 792 (2012)

10. J. H. Ward Jr, J. Am. Stat. Assoc., 58, 236-244 (1963)

11. T. Grabiński, A. Sokołowski, Zeszyty Nauk. Akad. Ekonom. w Krakowie, 181, 63-80 (1984)

12. E. Rollnik-Sadowska, E. Dąbrowska, Oeconomia Copernicana, 9, 1 (2018)

13. A. Małkowska, M. Głuszak, Oeconomia Copernicana, 7, 2 (2016)

14. Eurostat database. Available in: http://ec.europa.eu/eurostat/data/database

15. Research and Innovation Observatory of the European Commission. Available in: https://rio.jrc.ec.europa.eu /en/stats/new-doctoral-graduates-thousandpopulation-aged-25-34

16. Database of the World Bank. Available in: https://data.worldbank.org/indicator/IP.JRN.ARTC. SC? end $=2015 \&$ start $=2011 \&$ view $=$ chart

17. Innovation Union Scoreboard 2011. Available in: https://publications.europa.eu/en/publication-detail//publication/705c770c-68f7-4f90-ac2b-618cc6cc8e d7 /language-en/format-PDF

18. European Innovation Scoreboard 2016. Available in: https://publications.europa.eu/en/publication-detail//publication/6e1bc53d-de12-11e6-ad7c-01aa75ed7 1a1/language-en/format-PDF/source-31234102

19. U. Wich, Annales Universitatis Mariae CurieSkłodowska Lublin - Polonia, 51(1), 101-112 (2017)

20. European Innovation Scoreboard 2017. Available in: https://ec.europa.eu/docsroom/documents/24829 